\title{
DNA-directed DNA Polymerase
}

National Cancer Institute

\section{Source}

National Cancer Institute. DNA-directed DNA Polymerase. NCI Thesaurus. Code C16512.

Catalyses DNA-template-directed extension of the 3'- end of a DNA strand by one nucleotide at a time. Cannot initiate a chain de novo. Requires a primer, which may be DNA or RNA. (IUBMB Enzyme Nomenclature) 